\title{
A tensão como potência para teorizar a comunicação
}

\author{
Nísia Martins do Rosário' \\ https://orcid.org/0000-0003-3484-8029 \\ I - Universidade Federal do Rio Grande do Sul \\ Porto Alegre (RS), Brasil
}

\begin{abstract}
Resumo: Este artigo tem como propósito realizar uma abordagem da comunicação pela perspectiva da Semiótica da Cultura, trazendo reflexões de luri Lotman que contribuem para a problematização de paradigmas já assimilados pela área, expandindo o modo de entendê-la e de compor seus princípios. Com Lotman, por meio de conceitos como os de tensão, função criativa do texto, ruído e explosão, pode-se vislumbrar o potencial comunicativo dos processos que geram indeterminação de sentidos e estimulam a formação de novas tramas de tradutibilidade que vão constituir acréscimo de significados e até mesmo alterar a linguagem e os códigos - uma outra ótica para a comunicação.
\end{abstract}

Palavras-chave: tensão; ruído; semiótica da cultura.

Abstract: Tension as a potency to theorize communication - This article aims to carry out a communication approach from the perspective of Culture Semiotics, bringing reflections by luri Lotman, which contribute to the problematization of paradigms already assimilated by the area, expanding the way of understanding it and composing its principles. With Lotman, through concepts such as tension, creative function of the text, noise and explosion, one can glimpse at the communicative potential of the processes that generate indeterminacy of meanings and stimulate the formation of new translatability plots that will constitute an increase in meanings and even changing the language and codes - another perspective for communication.

Keywords: tension; noise; culture semiotics. 


\section{Diversas entradas}

As teorias da comunicação mais conhecidas e que deram início à consolidação do campo focam-se, principalmente, nas produções, nos efeitos, nas origens e nos funcionamentos dos meios, considerando diferentes perspectivas disciplinares, tais como sociologia, antropologia, filosofia, linguística e até matemática. Pode-se perceber que as abordagens seguem percursos tecnológicos, econômicos, políticos, cognitivos e sociais, de acordo com os contextos com os quais os pensadores estavam em conexão no momento de sua construção. Em outras palavras, entende-se que as teorias são fruto de um período histórico, do ambiente em que estão imersas e, portanto, da conjuntura espaço-temporal que as abriga.

A proposta deste texto é, pontualmente, ampliar o círculo desses olhares — vários deles de muita relevância — , incluindo uma perspectiva ainda pouco tratada nas ponderações da área e realizando uma abordagem da comunicação pela perspectiva da Semiótica da Cultura (SC), por meio dos apontamentos de luri Lotman. O artigo aborda o pensamento do autor, sua aproximação e superação da teoria cibernética da informação. Em seguida, apresenta o entendimento lotmaniano sobre o processo comunicativo, ao mesmo tempo em que explora e debate as potencialidades das suas concepções por meio de conceitos importantes como: tensão, ruído, função criativa da linguagem, tradução e explosão. Por fim, nas duas últimas seções, desenvolvem-se argumentos sobre a temática com vistas a contribuições às teorias da comunicação.

\section{A entrada lotmaniana}

As correntes semióticas consensualmente mais conhecidas são a estruturalista e a pragmaticista. A Semiótica da Cultura (SC), por sua vez, não se disseminou muito no mundo ocidental, provavelmente porque, no início, teve dificuldade de fazer circular a sua produção intelectual, que era escrita em russo originalmente. Grosso modo, seus estudos direcionam-se para a cultura, compreendida como linguagens e como forma de comunicação, entendendo-a como um problema semiótico.

Foi por meio da Escola Tartu-Moscou (ETM) ${ }^{1}$ que, na década de 1960, semioticistas russos criaram a Semiótica da Cultura, a partir do exercício teórico e 
da experimentação de ideias artísticas e científicas². É importante relembrar que a ETM emergiu em meio ao sistema soviético e em pleno desenvolvimento da cibernética, ramo da matemática que teve muita influência nesse período para o estudo em diferentes áreas. Da mesma forma que a ETM inicialmente, Lotman recebeu os influxos da cibernética em suas reflexões teóricas, mas, em um pequeno texto de quatro páginas publicado na obra Cultura y explosión $n^{3}$, ele coloca em xeque o modelo matemático e posiciona-se acerca da complexidade da comunicação. A partir desse texto e de outros escritos do autor, é que se propõe neste artigo uma abordagem da comunicação e um caminho para pensá-la teoricamente pelo viés do tensionamento, do ruído e da função criativa.

Para melhor entender a linha de raciocínio de Lotman, é importante, primeiramente, recuperar e desconstruir alguns aspectos da Teoria Matemática (ou Teoria da Informação - TI) elaborada pelo engenheiro Claude Shannon, o qual voltou sua proposta para a quantificação, o armazenamento e a transmissão da informação. Justamente por trazer uma teoria de perspectiva matemática, a TI não considerava a inserção social da comunicação, tampouco a interação, sendo, assim, um modelo apropriado para uma orientação unificadora que se restringia à transmissão de informação num padrão linear, com um mesmo volume de códigos — artificiais — e um mesmo volume de memória entre emissor e receptor. Tornou-se, portanto, um modelo pouco apropriado e consideravelmente limitado para pensar a comunicação, já que engessa o seu processo sem considerar a retroalimentação do sistema. Contudo, a Teoria da Informação, a partir do modelo criado por Shannon, teve muito prestígio na comunicação e está na episteme de diversas teorizações no campo.

Segundo Lotman (1990), não existe uma estrutura semiótica totalmente estável e imutável, o que impossibilitaria pensar a comunicação pela via da Tl, e, por outro lado, há uma falsa crença de que a função do mecanismo semiótico é transferir a mensagem adequadamente, ou seja, o texto ${ }^{4}$ recebido deve ser idêntico ao enviado, o que determinaria que o sistema teria trabalhado bem,

2 Vale lembrar aqui a Escola Formalista russa, que, a partir de seus autores, teve reflexos sobre o pensamento da ETM. Ekatarina Volkova Américo (2013) destaca as influências de Mordóvtchenko e Propp como professores de Lotman e dos fundadores do formalismo russo, Boris Eichenbaum e lúri Tyniánov. Esse último, segundo a autora, ao desenvolver o esquema de automatização/ desautomatização (junto com outros formalistas), permite a Lotman criar o próprio modelo de mecanismo de dinâmica da cultura. Já Irene Machado (2003) menciona como Lomonóssov contribuiu com o pensamento da Escola Tartu-Moscou deixando um legado para o estudo da linguagem.

3 O título do capítulo 2 de Lotman, em Cultura y explosión (1999), é "El modelo monolinguístico" (p.15-18).

4 Para Lotman, o texto é a unidade básica da semiótica. 
contando com uma estrutura estável. “Essas diferenças são classificadas como 'erros' e existem mecanismos especiais na estrutura (por exemplo, redundância) para evitá-los" (LOTMAN, 1990, p. 12, tradução nossa).

A partir desse ponto de vista, a Teoria Matemática leva o conceito de comunicação a uma adequação/redução: os ruídos são sempre considerados obstáculos, devido a alguma imperfeição técnica, e as redundâncias estão sempre presentes, a fim de diminuir as incertezas por meio das repetições. Esse seria, então, para o autor, um modelo ideal de comunicação, uma vez que os ruídos poderiam ser eliminados e as redundâncias, repetidas, enquanto enunciador e enunciatário deveriam ter uma mesma identidade, que configuraria um mesmo volume de códigos e um mesmo volume de memória. Da mesma forma, o entendimento do código sustentaria a ideia de estrutura artificial, criada a partir de um consenso, sem supor a história e a cultura. Só se poderia alcançar uma mesma identidade entre enunciador e enunciatário se a transmissão de informação se configurasse num mesmo código e dentro de uma estrutura sem memória.

Isso garantiria a comunicação ideal e uma transmissão perfeita, porém rebaixaria o valor da informação, limitando-a, já que a mensagem se configuraria pela impossibilidade de polifonia, trazendo o mínimo de incompreensão. Nessa via, o modelo matemático se constituiria apenas na relação com a lógica e, mais ainda, pela inteligência artificial própria de operações algorítmicas. Seria, então, uma comunicação que dificilmente se realizaria no âmbito do humano, já que não atenta para a memória e a dinâmica transformadora das linguagens e da cultura.

Para a TI, o código tem ligação com a redundância, uma vez que esta facilita a exatidão da decodificação e é um teste para identificar os erros, visando à exatidão da mensagem, e, nessa via, se aproxima dos códigos da informática. É preciso ter em conta, todavia, que o fato de os sujeitos comunicantes usarem uma mesma linguagem não garante uma identidade de código (que é sempre relativa), pois eles precisariam também de uma mesma (ou análoga) compreensão das regras, uma mesma (ou similar) experiência e referência de linguagem e dimensões de memória parecidas.

O modelo comunicacional monolinguístico ${ }^{5}$, portanto, é uma ilusão, pois só se realiza na abstração, tendo como única função a transmissão de informação, 
porque opera sobre uma condição ideal de comunicação — em tal condição, a mínima alteração implica erro e distorção semântica.

\section{A entrada lotmaniana na comunicação}

Lotman (1999, 2000) configura outro raciocínio para pensar a comunicação, problematizando-a também pela via da linguagem, do código e da memória, que atravessam os espaços-tempos dos interlocutores. Já bastante estudado, o modelo considerado mais adequado para representar a comunicação seria o da intersecção, que, na obra Cultura y explosión (1999), é concebido no encontro de dois círculos ou esferas (Figura 1), enquanto na obra Universe of mind (1990), é mostrado de modo mais complexo.

\begin{tabular}{|l|r}
\hline $\begin{array}{l}\text { Espaço de } \\
\text { não intersecção }\end{array}$ & $\begin{array}{r}\text { Espaço de } \\
\text { INTERSECção }\end{array}$ \\
& $\begin{array}{l}\text { Espaço natural } \\
\text { de comunicação }\end{array}$
\end{tabular}

Em geral, quando pensamos em interação ou interlocução, o espaço de encontro e convergência pela intersecção dos interlocutores se evidencia como ambiente natural da comunicação. No diagrama (Figura 1), é possível perceber que há uma região comum entre interlocutores, em que é possível vislumbrar o domínio similar, que permite determinado nível de identidade entre códigos e linguagens e segue uma tendência que visa colaborar com a compreensão das mensagens. É fácil depreender que esse espaço tem por função facilitar o processo de tradução e, ao mesmo tempo, fortalecer o campo comum, promovendo cada vez mais as trocas de informação. É um 
ambiente em que o ruído tende a ser mínimo e a redundância tende a ser elevada. Diante disso, é possível vislumbrar um ambiente de maior segurança, em que os sistemas modelizantes ${ }^{6}$ estão mais unificados, assim as regularidades, as continuidades e as previsibilidades se fazem presentes. Os exemplos mais diretos seriam os enunciados como: Pare!; Não pise na grama.; Que horas são?.

Por outro lado, esse diagrama (Figura 1) também deixa evidente um território de não intersecção, ou seja, em que não há partilha comum. O semioticista russo nos lembra, por essa via de raciocínio, que a extensão territorial da intersecção e da não intersecção é variável de acordo com as competências dos interlocutores em coordenar linguagem, código e memória. É possível pensar que tais espaços podem se cruzar em diferentes níveis e com diversas intensidades e que, ao mesmo tempo em que parecem contraditórios, eles são complementares. Pelo ponto de vista de Lotman (1999, p. 18), a "vitória exclusiva de algum desses polos [intersecção ou não intersecção] representaria a destruição da informação que se cria no campo de sua tensão recíproca" (tradução nossa).

Em princípio, pode-se compreender que o espaço natural da comunicação seria constituído no âmbito da intersecção e, a partir desse entendimento, seria possível defender que quanto mais se estende a superfície de convergência semiótica, mais abundante e vigorosa seria a comunicação. Sobre a intersecção, o autor defende que o intercâmbio de informações realizado nas partes que se cruzam pode sofrer do vício da trivialidade, já que as opções para a construção dos textos se centram em escolhas comuns e recorrentes, tendo em vista a compreensão facilitada da mensagem. Ele elabora, portanto, uma problematização sobre o espaço mais tradicional da comunicação, chamando a atenção para a sua banalidade, despretensão e simplicidade.

É na não intersecção que se encontra o ponto de vista relevante de Lotman em relação à comunicação. Ao contrário do que se realiza no espaço de intersecção, é possível prever que nesse ambiente se encontra menor segurança comunicativa, porque os sistemas modelizantes não estão tão ajustados e, assim, evidenciam-se as irregularidades, descontinuidades e

6 Os sistemas modelizantes constituem-se como um complexo de signos que se organizam a partir de um conjunto de regras, normas, códigos, enfim, de determinadas estruturas; tais sistemas estão divididos em primário e secundário. O primário institui-se a partir da língua natural considerando suas estruturas, e o sistema modelizante secundário se estabelece por meio de estruturalidades encontradas em outras linguagens — esse é o sistema da cultura. 
imprevisibilidades. Alteram-se as modalidades, e o ruído tende a ser elevado, enquanto a redundância tende a ser mínima.

Para problematizar os modelos que tentam explicar a comunicação humana, então, o semioticista russo parte da não intersecção, ou seja, de uma não identidade de base entre enunciador e enunciatário, o que significa que os sujeitos comunicantes não operam sobre conhecimento e uso equivalentes de códigos, memória e linguagem. Ainda que não haja uma identidade muito similar entre eles, há determinado nível de interação propiciado por espaços de linguagem partilhados.

O valor do diálogo não está ligado à parte que se intersecciona, mas à transmissão de informação entre as partes que não se interseccionam. [...] quanto mais difícil e mais inadequada é a tradução de uma parte não interseccionada do espaço à língua da outra, mais preciosa se torna, nas relações informacionais e sociais, o feito dessa comunicação paradoxal (LOTMAN, 1999, p.17, tradução nossa).

Para complementar a reflexão, é relevante trazer a noção de dialogismo de Bakhtin (2011), que se constitui na linguagem e dá ênfase à relação comunicativa entre os sujeitos, considerando a importância de aspectos históricos, ideológicos e dialógicos. Para o autor, todos os integrantes do processo comunicativo estão em interação e são, portanto, ativos e responsivos, constituindo a linguagem como uma prática social.

O que parece mais importante para essa abordagem é que a perspectiva dialógica diz respeito ao modo de funcionamento da linguagem, no qual diferentes vozes sociais constituem um espaço de luta que se materializa nos discursos, atravessados por pontos de vista díspares, porém não necessariamente contraditórios. Assim, o dialogismo incorpora essas vozes e seus modos específicos de composição de enunciados, tornando comunicação e discurso dependentes dessa sociabilidade. Bakhtin, portanto, superou a dicotomia forma-conteúdo e integrou à linguagem a experiência social.

Nessa via, é possível articular o pensamento bakhtiniano ao lotmaniano pelo dialogismo, que se constitui no processo comunicativo a partir de um ambiente de lutas ideológicas e que, se deduz, é gerador de tensão (noção articulada por Lotman). Essas lutas são admitidas porque os sujeitos comunicativos têm possibilidade de ação sobre a linguagem, uma vez que nem sempre estão inclinados a concordarem com os discursos. Essa perspectiva pode ser percebida nas colocações lotmanianas a partir da não intersecção 
no processo comunicativo, que poderiam se constituir como a demarcação dos espaços de luta propostos por Bakhtin.

A partir dessas colocações, é possível verificar a potência do ruído e do código no processo de comunicação e concordar com Lotman (1999) que a condição de fato da comunicação é a da imprevisibilidade e das transformações complexas que se configuram em conexão com a não intersecção, sendo essa condição atravessada pelo ruído para chegar à tensão.

Se no modelo da teoria da informação o ruído é uma anomalia que deve ser descartada, na perspectiva apresentada por Lotman, ele é configurador de novos sentidos. De certa forma, o que se busca na perspectiva comunicacional do semioticista não é a redundância, mas o ruído - que tem papel especial como elemento capaz de interferir em todo e qualquer processo comunicacional.

Esse ponto de vista traz à tona a potencialidade criativa e dialógica da comunicação, que se orienta para aquilo que é denominado ruído e pode ser complementada por abordagens de outros autores, como Barbosa Filho (2003), que o entende como uma interferência na comunicação que tanto pode se configurar como gerador de novidade como de estranhamento. Para o autor, esse último seria um efeito de sentido capaz de suscitar a renovação no processo de significação do objeto, constituindo-se numa maneira especial de conhecimento. O estranhamento torna-se importante para entender os espaços de não intersecção da comunicação, porque opera sobre as potencialidades de decodificação do ruído e até de incorporação do estranho que, momentaneamente, é externo ao sistema ou faz parte das imprevisibilidades. Assim, um aspecto desejável do ruído é a possibilidade de desabituar o processo interpretativo e operar sobre tradutibilidades antes não pensadas e geradoras de polifonia (polissemia). Existe aí um potencial de transformação pela tensão gerada no sistema de tradução e pelas disputas de sentidos.

Outro aspecto que deve ser considerado na problematização dos espaços de não intersecção propostos por Lotman é a noção de código, o qual não se configura de forma igual na dimensão do emissor e na dimensão do receptor, tampouco inclui uma estrutura criada, mas, sobretudo, supõe a história e a existência de uma memória. Considerando as indicações de Lotman (1990, 1999, 2000a), pode-se entender que o código deve ser pensado na relação com a história e com a dinamicidade da cultura, de modo que está em constante atualização. Além disso, há nele também uma série 
de hierarquias que se organizam a partir do movimento da cultura e, por consequência, dos sistemas semióticos.

Ainda que isso não tenha sido defendido pelo autor, o código não é unívoco e está em constante mutação. Não é possível, portanto, entendê-lo pela visão binária para a construção de um conjunto de regras para codificar e decodificar uma mensagem. Umberto Eco (1974) oferece elementos sobre o código a serem levados em consideração, ao estudá-lo numa dimensão cultural a partir de convenções estabelecidas e criadas nesse âmbito, comparando-o a uma estrutura rizomática pluridimensional e a um sistema de regras. Na perspectiva diacrônica, o autor defende que os códigos mudam, estão em constante transitoriedade, assumindo um processo de contestação e modificação, que é acionado quando as mensagens assim o exigem, gerando uma codificação extra, materializada na supercodificação e na subcodificação. O autor também defende que os códigos do emitente e do destinatário podem diferenciar-se parcial ou integralmente, assim como seus percursos de leitura, colocando em jogo a decodificação (tradução) e o processo de produção de sentidos - do que se pode deduzir que seriam gerados espaços de não intersecção.

Nessa via, entendemos que o processo comunicacional se enriquece pelos tensionamentos que vão se formando nos espaços de não intersecção e se constituem como ambientes de criação e de novidade por meio dos ruídos e da transitoriedade dos códigos. A semiotização realizada nessa tensão propulsiona movimentos e mutações nos sistemas que envolve, dá-se com mais potência nas fronteiras da semiosfera ${ }^{7}$ e igualmente nas partes não interseccionadas do modelo de comunicação proposto por Lotman.

A comunicação, então, vai construindo seus movimentos em duas direções pelo menos: a da previsibilidade e a da imprevisibilidade. Ambas se estimulam reciprocamente, relacionando-se de forma dinâmica por sucessão e por simultaneidade de vários estados. Seu funcionamento recíproco, mas igualmente consolidado na oposição, provoca respectivamente a estabilização e a desestabilização. Essa última é definida como uma linha de desenvolvimento que salta para uma nova: imprevisível e mais complexa - explosão.

A princípio, pode-se considerar a não intersecção, por si só, como um lugar de impossibilidade da comunicação, sendo, dessa maneira, excluída do diálogo.

7 Semiosfera configura um espaço de realização da comunicação. Entendemos que ela deve ser tomada como uma dimensão na qual se manifesta o que é próprio da significação, da semiose, um ambiente em que circula a semioticidade. 
Todavia, é possível prever, acompanhando a reflexão de Lotman (1990, 1996, 1999), a transmissão de informação entre as partes que não se interseccionam. Ele reconhece que, à primeira vista, seria uma contradição, mas justifica: "estamos interessados na comunicação justamente por causa dessa situação que torna difícil a comunicação e que, no limite, a faz impossível" (LOTMAN, 1999, p. 17, tradução nossa). A relevância do diálogo, então, está justamente na possibilidade de uma indeterminação de sentidos.

Dessa forma, é possível depreender que quanto mais difícil e inadequada é a tradução de uma parte para outra, mais relevante é o estudo dessa comunicação paradoxal nas relações informativas e sociais. Isso permite afirmar que existem diversos graus de tradutibilidade e intradutibilidade no espaço da não intersecção e que seu tensionamento tem, entre outras funções, a tarefa de atualizar os métodos de geração de sentido.

Infere-se, portanto, que o traço distintivo do texto semiótico é a heterogeneidade e que a tendência é acrescentar valor à mensagem, ampliar as possibilidades de sentido e reconhecer, cada vez mais, as diferenças entre os sujeitos comunicantes, trazendo amplitude para o processo comunicativo quando se realiza a tradução do parcialmente tradutível ou do intraduzível. Ao afirmar que a não compreensão é um mecanismo de sentido tão importante quanto a compreensão, Lotman instaura uma janela para a entrada da noção de tensão no processo de comunicação e pontua, ainda, que o que o espaço de intersecção considera um erro, no ambiente da não intersecção é a norma.

\section{Refletindo sobre um conceito-chave: tensão}

Uma noção forte a ser conectada às noções de ruído e de código, no desdobramento da reflexão de Lotman, é a de tensão, compreendida como certa resistência de forças inserida no processo comunicativo e que se realiza entre o espaço da intersecção e o da não intersecção. O autor não se aprofunda muito nessa concepção, contudo, é possível pensar que o tensionamento recíproco que aí se estabelece é o que mantém viva - em movimento - a comunicação por meio de formas de contato que propiciam deslizamentos diversos, os quais oscilam desde a facilidade da compreensão até seu polo oposto, a intradutibilidade. É nesse processo de tensionamento que se constroem a resistência de forças e a comunicação criativa e no qual as lutas e disputas de sentidos se realizam. A tensão, ao mesmo tempo que 
interpela os códigos propulsionando a sua atualização, permite a reorganização inventiva dos signos num texto e a orientação para novas semioses a partir da indeterminação de sentidos. Os ruídos são os potenciais tensionadores do processo comunicativo, inquirindo o próprio código e os processos de tradutibilidade dos sujeitos. Empregam-se, nesses movimentos, várias velocidades de transformação, considerando arranjos já costumeiros tanto quanto desarranjos criativos.

De tal modo, pode-se defender que a comunicação sai de seu viés de transmissão linear para inserir-se numa configuração mais complexa que percebe, sobretudo, os andamentos desse campo, os quais se dão em diversas direções e intensidades. É importante destacar, especialmente, a importância da resistência de forças capaz de estabelecer tensionamentos que se manifestam nas disputas de sentidos nos diversos estratos, bem como na tentativa de ampliar o campo de intersecção e, igualmente, na de ampliar cada vez mais as diferenças entre os sujeitos comunicantes.

Pode-se complementar essa abordagem do tensionamento entre a intersecção e a não intersecção com a perspectiva construída pelo próprio Lotman (1990) sobre a função criativa da linguagem ou do texto. Ela se manifesta na comunicação na medida em que coloca em conexão as partes que não se interseccionam e, assim, permite a concepção de novos textos gerados nas forças de resistência e nos tensionamentos do processo comunicativo, operando como "dispositivo pensante" (LOTMAN, 1996). São os textos que não se pode prever ou que se pode prever só relativamente, como por exemplo o filme $M a \tilde{e} e^{8}$, diante do qual o espectador precisa de pistas do diretor para colocar o processo de interpretação em andamento, o qual é tensionado por contextos religiosos bíblicos, bem como míticos da deusa-mãe geradora da vida, da natureza, da fertilidade e da cultura, mas ainda se abre para outras compreensões. Em textos como esses, pode-se verificar a explosão de sentidos que se dá em diversas direções, provocando tensões no processo de tradução.

Na arte está a amostra mais direta de textos novos articulados sobre a função criativa da linguagem, no entanto, também se enquadram nessa configuração os textos de outras culturas e os formados casualmente. Exemplo desses últimos está nos desdobramentos da pandemia da covid-19, que, imprevisivelmente, afetou o mundo nesse ano de 2020, formatando novos 
textos em relação aos modos de convivência (isolamento social), às configurações do trabalho, aos procedimentos da ciência, aos processos da educação formal, entre tantos outros. A grande maioria dos humanos vivos no planeta não tinham provado experiências como essas e se depararam com alterações nos códigos, novos usos das linguagens e a necessidade de ressignificar os sentidos de higiene, interação humana, preservação da saúde, solidariedade e assim por diante ${ }^{9}$.

Em todas as situações pode acontecer de o enunciatário se deparar com uma linguagem desconhecida ou um texto inusitado e precisar conhecer e/ ou reconstruir códigos e significados. A busca da significação está sempre em movimento, e, mesmo em casos mais complexos, antes de prosseguir a semiose, o enunciatário busca descobrir algumas indicações sobre quais códigos estão associados à mensagem e como deve decodificá-los.

É consenso que a tradução é elemento fundamental no processo comunicativo, mas é imperativo ir mais adiante e problematizar a relação da tradução e da função criativa, sobretudo quando o tradutor se depara com códigos multidimensionais que se conformam numa complexa construção hierárquica, constituída por relações assimétricas e demandando a necessidade constante de escolhas. Nesse cenário, a tradução identifica um novo texto e coloca em movimento as ferramentas do sistema para (re)organizar o processo interpretativo. Assim, segundo Lotman (2014), a combinação entre tradutibilidade e intradutibilidade é o que determina a função criativa, sendo que a tradução se torna importante porque, quando realizada em sistemas complexos de códigos, se articula nas resistências de forças.

Para finalizar, defende-se que a perspectiva de Lotman (1999) sobre a comunicação, que reconhece a relevância da conexão entre espaços de intersecção e não intersecção prevendo a possibilidade de indeterminação de sentidos, pode ser complementada por seu conceito de explosão. Esta se articula a partir de um complexo potencial de trajetórias de sentidos, nem sempre sendo possível prever o estado seguinte. A explosão ${ }^{10}$, portanto, é

9 Esse assunto renderia páginas e páginas de abordagem acadêmica. Como não é o objetivo deste artigo tratar desta explosão semiótica, a aproximação fica limitada a este pequeno parágrafo. Pode-se ler mais em: ROSÁRIO, 2020.

10 Ao afirmar que o momento da explosão é o momento da imprevisibilidade, Lotman, contudo, faz uma ressalva: não se pode entender a imprevisibilidade fora do contexto dos sistemas, ou seja, há uma lógica daquilo que pode ser considerado imprevisível. 
o lugar de um brusco aumento da informatividade de todo o sistema, que num primeiro momento causa incompreensão, uma vez que "a curva de desenvolvimento salta a uma via completamente nova, imprevisível e mais complexa" (LOTMAN, 1999, p. 28, tradução nossa).

Nessa concepção, é bom lembrar que os limites dos espaços de intersecção são formados por uma multiplicidade de usos e que o espaço da semiótica da explosão pode ser entendido como uma intersecção em vários níveis de vários textos que, unidos, vão formar determinado estrato, com complexas relações internas, diferentes graus de tradutibilidade e espaços de intradutibilidade. Nessa perspectiva, o semioticista russo destaca que a inspiração criativa pode ser entendida como uma tensão suprema (explosão) e, para chegar ao nível da criação imprevisível, arranca o homem da esfera da lógica. Nesse processo, os códigos se atualizam em diferentes velocidades, o incompatível se transforma em adequado e o intraduzível, em traduzível.

\section{Um viés teórico para a comunicação a partir de Lotman}

Ao encaminhar o fechamento deste artigo, há aspectos importantes a serem realçados, a fim de sublinhar o que se entende como mais relevante em toda essa abordagem. Em primeiro lugar, a perspectiva lotmaniana aqui abordada e desdobrada tem potencial como um ponto de vista aguçado sobre o processo comunicacional que consegue distinguir particularidades não visibilizadas ou muito pouco abordadas por outros autores, ao fazer figurar com protagonismo o conceito de tensão provocado entre espaços de intersecção e não intersecção e, nesse sentido, evidenciar o papel do ruído, dos códigos, da explosão e da função criativa da linguagem.

As reflexões do autor permitem desenvolver um pensamento mais complexo em relação à comunicação, evidenciando um modo de raciocínio que desestabiliza o processo, bem como conceitos aplicados em teorias já existentes. Não se pode entender essa perspectiva sem verificar que os interesses da SC se concentram no texto ${ }^{11}$ e nos sistemas de linguagens, direcionando a atenção, portanto, às performances comunicacionais na relação com a cultura, bem como a suas dinâmicas, funcionamentos e organização.

Entende-se que as principais contribuições do semioticista russo para a comunicação são: a potência que ele consegue dar ao conceito de tensão e 
o modo como captura e concebe o processo e o território comunicacional, partindo de uma metalinguagem própria. Ao afastar-se de um modelo ideal à procura de pontos de contato com elementos do sistema que não circulam costumeiramente nos estudos da área, Lotman descobre a condição de relevância de sua pesquisa. O ponto fundamental está justamente na situação paradoxal que se cria entre os espaços de convergência (intersecção) e de não convergência (não intersecção) semiótica. O que torna difícil a comunicação é o foco de interesse de Lotman, porque aí se estabelecem os processos criativos.

Constitui-se aí um transbordamento dos mais usuais conceitos de comunicação, que desloca a definição para além dos ambientes de convergência semiótica, levando em conta também aquilo que está fora desse espaço e que, portanto, facilmente se consideraria como erro, defeito, falha, não ideal. Essa desterritorialização de elementos anteriormente desprezados, com vistas a articular um modo amplificado de conceber o processo e o território comunicacionais, permite a potencialização da resistência de forças que se manifestam nas disputas de sentidos.

O processo comunicacional, deste ponto de vista, não ocorre mais somente no território natural da comunicação, mas igualmente pode acontecer em zonas inadvertidas, em terras alheias. Isso significa que, muitas vezes, nos deparamos com textos que estão fora das nossas competências semióticas, aos quais dedicamos o benefício da semiose, mas que levam a uma predição que está cheia de indeterminação de sentidos. Assim, para nos aproximarmos de uma interpretação mais precisa, temos que ampliar nosso campo de intersecção. Além disso, o processo também pode ficar nas bordas das convergências, permitindo a formação de sentidos periféricos (não ideais). E, ainda, é possível prognosticar que o movimento de tradução se construa na não compreensão ou que utilize apenas alguns elementos da zona de intersecção.

Todos esses deslocamentos acabam por tensionar o sistema, provocando instabilidades de diversas ordens que vão colocar em negociação lógicas variadas que coexistem na semiosfera e que podem produzir desde a compreensão até a incompreensão, e levar à criação, à confusão ou à falsificação. O problema se dá quando o sistema se apodera da indeterminação de sentidos ou da incompletude dos textos para estabelecer sentidos falsos, adulterados ou deformados com objetivos doutrinários e enganadores. 
Muitas vezes, quando a redundância é minimizada e o ruído é elevado à potência criativa pela ocupação de zonas de não convergência, está se exibindo uma reação aos modelos racionalizantes e reducionistas que inserem a comunicação num território ideal, mas quimérico. Os textos construídos sobre a trivialidade de repetições, continuidades e previsibilidades têm potencial para caminhar rumo às totalizações e universalizações e, consequentemente, aos estereótipos e preconceitos que acabam formando sentidos falsos.

Afinal, como defende Lotman, a não compreensão é um mecanismo de sentido tão importante quanto a compreensão e mais uma vez leva a pensar que o fundamental é estudar o processo desses mecanismos e não a razão de sua aplicação. Encontram-se facilmente produtos comunicacionais que nos fazem transitar entre zonas de compreensão e de não compreensão com uma larga escala de possibilidades de tradução. Pode-se citar o livro As aventuras de Alice no País das Maravilhas ${ }^{12}$, que abre várias linhas de leitura e no qual a tradução semiótica torna-se difícil em função de a obra assumir a lógica do absurdo e se construir no gênero nonsense - um desafio ao repertório do leitor e à sua criatividade. Ou, então, a pintura Monalisa ${ }^{13}$ que, com mais de 500 anos, ainda provoca dúvidas na tradução de sua aparência (se expressa ou não um sorriso) e, ao gerar ambiguidade, mostra a genialidade da obra, constitui um poliglotismo interno e, portanto, mecanismos de formação de sentidos. Essas obras, entre outras, estão recheadas de absurdo, impossibilidades, referências enigmáticas, descontinuidades e imprevisibilidades que determinam certo nível de não compreensão - é a comunicação atravessando o campo da não intersecção.

Ao voltar a sua atenção para esses aspectos da comunicação, o semioticista russo conseguiu vislumbrar o potencial da tensão sobre os movimentos comunicacionais, problematizando os sistemas de linguagens já bastante modelizados pelas escolhas recorrentes e viciados no ordinário, criando, assim, facilidade de condução do processo pela repetição e pela continuidade. Afinal, os textos que se repetem não exigem esforço de decodificação e interpretação.

O processo comunicacional é enriquecido pela tensão justamente porque ativa o dispositivo pensante, tanto no âmbito da produção quanto no da tradução, interpelando os processos, recusando repetições, continuidades 
e previsibilidades. Nesses casos, a semiotização propulsiona movimentos de mutações nos sistemas que envolve, e o significado "não é apenas um invariante remanescente que é preservado sob todos os tipos de operações transformacionais, mas também é alterado, podemos afirmar que há um acréscimo de significado no processo de tais transformações" (LOTMAN, 1990, p. 15, tradução nossa). Esses movimentos paradoxais, que operam sobre a possibilidade da intradutibilidade, vão compondo diferentes tramas de sentido, porque necessitam ser codificados e decodificados a cada vez. É nesta via que é possível afirmar, com Lotman, que a condição de fato da comunicação é a da tensão, da imprevisibilidade e das transformações complexas, que se configuram em conexão com a não convergência semiótica e com as lutas e disputas de sentidos.

Nísia Martins do Rosário é professora da Universidade Federal do Rio Grande do Sul, no curso de Comunicação Social e no Programa de Pós-Graduação em Comunicação e Informação. É doutora em Comunicação Social pela PUC-RS e mestre em Semiótica pela Unisinos. É bolsista Produtividade em Pesquisa CNPq. Coordenou o GP Semiótica da Comunicação da INTERCOM (2019-2020). Foi vice-presidente da COMPÓS (2019-2020). Coordenou o Programa de Pós-graduação em Comunicação e Informação PPGCOM/UFRGS (2015-2016). É membro dos grupos de pesquisa GPESC (Grupo de Pesquisa Semiótica e Cultura da Comunicação) e PROCESSOCOM (Processos Comunicacionais: Epistemologia, Midiatização, Mediações e Recepção), que é organizador da REDE AMLAT (Rede Temática Comunicação, Cidadania, Educação e Integração na América Latina).

nisiamartins@gmail.com

\section{Referências}

AMÉRICO, E. V. Iuri Lotman: entre a biografia e a obra. RUS (São Paulo), v.2, n.2, p. 67-83, 2013.

BAKHTIN, M. Estética da criação verbal. 6ed. São Paulo: Martins Fontes, 2011.

BARBOSA FILHO, H. Ruído, estranhamento, comunicação. In: . 0 giz e a letra. João Pessoa: Manufatura, 2003.

ECO, U. As formas do conteúdo. São Paulo: Perspectiva, 1974. 
LOTMAN, I. A estrutura do texto artístico. Lisboa: Estampa, 1978.

__ La Semiosfera I. Semiótica de la cultura y del texto. Madrid: Catedra, 1996.

La Semiosfera II. Semiótica de la cultura y del texto, de la conducta y del espacio. Madrid: Catedra, 2000a.

La Semiosfera III. Semiótica de las artes y de la cultura. Madrid: Catedra, 2000b.

Cultura y explosión. Barcelona: Gedisa, 1999.

Universe of the Mind. A Semiotic Theory of Culture. Bloomington: Indiana University Press, 1990.

MACHADO, I. Escola de semiótica. São Paulo: Ateliê Editorial/FAPESP, 2003.

ROSÁRIO, N. M. Explosões semióticas na pandemia do covid-19. In: MUNHOZ, A.V.; COSTA, C.B.; LULKIN, S.A. (Orgs.). Porque esperamos: notas sobre a docência, a obsolência e o vírus. Porto Alegre: UFRGS, 2020.

Ensaio recebido em 09/05/2020 e aprovado em 29/07/2020. 